Archives de sciences sociales des religions

184 | octobre-décembre 2018

Bulletin bibliographique

\title{
Massimo INTROVIGNE, The Plymouth Brethren
}

New York, Oxford University Press, 2018, 141 p. Index, bibliographie, photos.

\section{Régis Dericquebourg}

\section{(2) OpenEdition}

Journals

Édition électronique

URL : https://journals.openedition.org/assr/44960

DOI : $10.4000 /$ assr. 44960

ISSN : $1777-5825$

Éditeur

Éditions de l'EHESS

Édition imprimée

Date de publication : 1 décembre 2018

Pagination : 309-310

ISSN : 0335-5985

\section{Référence électronique}

Régis Dericquebourg, "Massimo INTROvIGNE, The Plymouth Brethren », Archives de sciences sociales des religions [En ligne], 184 I octobre-décembre 2018, mis en ligne le 01 décembre 2018, consulté le 16 janvier 2022. URL : http://journals.openedition.org/assr/44960 ; DOI : https://doi.org/10.4000/assr. 44960

Ce document a été généré automatiquement le 16 janvier 2022.

(C) Archives de sciences sociales des religions 


\title{
Massimo INTROVIGNE, The Plymouth Brethren
}

\author{
New York, Oxford University Press, 2018, 141 p. Index, bibliographie, \\ photos.
}

\section{Régis Dericquebourg}

\section{RÉFÉRENCE}

Massimo INTROVIGne, The Plymouth Brethren, New York, Oxford University Press, 2018, 141 p. Index, bibliographie, photos.

En 123 pages de texte, Massimo Introvigne parvient à faire une présentation historique et à dresser un état des lieux présent des diverses ramifications issues de la prédication chrétienne évangélique de John Nelson Darby (1800-1882). Ce dernier est considéré comme le théologien qui a systématisé le dispensationalisme (thèse de la division de l'histoire en une succession de périodes qui sont les étapes successives du retour du Christ et de la parousie). Darby est connu pour avoir rejeté l'institutionnalisation des groupes de croyants ainsi que toute forme de clergé, deux éléments qu'il jugeait incompatibles avec le christianisme. En théorie, les croyants qui se rallient aux vues de Darby ne peuvent donc que former des communautés spirituelles informelles qui ne font que partager ensemble la Cène. On trouve là un radicalisme anti-organisationnel équivalent aux agrégats de libertaires hostiles à toute forme de groupement gouverné par un règlement et une autorité quelle qu'en soit la forme. Les premiers suiveurs de Darby ont constitué ce type d'unions informelles de croyants à Plymouth. De ce fait, les disciples de Darby ont pris le nom de "Frères de Plymouth" (Plymouth Brethren). Paradoxalement, le refus de l'autorité et de l'institutionnalisation n'a pas empêché leurs partisans de se diviser à cause de divergences morales et théologiques. La fragmentation des Darbystes est importante, elle ressemble à la postérité de Charles Taze Russell (1852-1916) composée des Témoins de Jéhovah et de dizaines de groupes russellistes dont le nombre de fidèles est parfois infime. Un des intérêts majeurs du 
livre de Massimo Introvigne est d'éclairer le lecteur sur ce foisonnement de groupements scissionnistes dont l'appellation va de Brethen I jusqu'à Brethen X. Un tableau récapitulatif (p. 86-88) les met en perspective et indique dans une colonne l'origine de chacun d'eux et dans une autre colonne leur développement historique, numérique et géographique. Il faut saluer l'esprit méthodique qui sert la clarification de cet univers spirituel. Selon nous, l'autre intérêt majeur du livre est sociologique. Il porte sur la relation avec la société globale de groupes qui cultivent une séparation "salutaire » avec elle. L'auteur montre que la séparation est " poreuse » car ils jouent le jeu social pour rendre à "César ce qui est à César » et à "Dieu ce qui est à Dieu ». Nous avions repéré cette fausse rupture avec la société globale chez les Témoins de Jéhovah qui se séparent du "monde" considéré comme non chrétien et source potentielle de contamination immorale mais qui vivent à l'intérieur de celui-ci (Régis Dericquebourg, Les Témoins de Jéhovah dans le Nord de la France. Implantation et rapport à l'institution, thèse EPHE, 1979). Massimo Introvigne montre qu'à une époque, qu'il qualifie de postmoderne, les Frères de Plymouth gagnent une crédibilité sociale en s'engageant dans les œuvres humanitaires au nom des valeurs chrétiennes dites traditionnelles (p. 90-92). L'auteur relate les débats de la "Charity commission" britannique qui a officialisé par une reconnaissance officielle l'investissement des branches des Frères de Plymouth dans les actions charitables. Enfin, l'auteur accorde quelques pages aux attaques de la Mission interministérielle de vigilance et de lutte contre les dérives sectaires (Miviludes) française et en particulier à la critique de leur école de Chambon sur Lignon avant même que celle-ci n'ouvre. Les inspecteurs d'académie furent moins critiques et conseillèrent simplement aux enseignants d'accueillir des élèves de familles «non brethren " pour éviter l'isolement comme ce fut le cas des Enfants de Dieu (devenu La Famille) dans les années 1990 (Rapport Morachini, Benoist et George, 2014).

2 Massimo Introvigne nous a habitués aux synthèses très bien documentées et très méthodiques comme, par exemple, Les veilleurs de l'apocalypse (Paris, 1996) ou encore L'Enquête sur le satanisme (Paris, 1997), mais celle-ci est un chef-d'œuvre du genre puisqu'en 123 pages, il donne une perspective diachronique, synchronique des Assemblées de Frères, fondée sur 187 références bibliographiques. L'ouvrage, très lisible est probablement la synthèse la plus complète disponible actuellement sur le Darbysme. 